This item was submitted to Loughborough's Research Repository by the author.

Items in Figshare are protected by copyright, with all rights reserved, unless otherwise indicated.

\title{
Usage, barriers and measurement of social media marketing: an exploratory investigation of small and medium B2B brands
}

PLEASE CITE THE PUBLISHED VERSION

http://dx.doi.org/10.1016/j.indmarman.2011.09.009

\section{PUBLISHER}

(C) Elsevier

VERSION

AM (Accepted Manuscript)

\section{PUBLISHER STATEMENT}

This work is made available according to the conditions of the Creative Commons Attribution-NonCommercialNoDerivatives 4.0 International (CC BY-NC-ND 4.0) licence. Full details of this licence are available at: https://creativecommons.org/licenses/by-nc-nd/4.0/

\section{LICENCE}

CC BY-NC-ND 4.0

\section{REPOSITORY RECORD}

Michaelidou, Nina, Nikoletta Theofania Siamagka, and George Christodoulides. 2019. "Usage, Barriers and Measurement of Social Media Marketing: An Exploratory Investigation of Small and Medium B2B Brands". figshare. https://hdl.handle.net/2134/15705. 


\title{
Usage, Barriers and Measurement of Social Media Marketing: An Exploratory Investigation of Small and Medium B2B Brands
}

\author{
Nina Michaelidou \\ Department of Marketing \\ The Birmingham Business School \\ University of Birmingham \\ E: N.Michaelidou@bham.ac.uk \\ T: 01214148318
}

Nikoletta Theofania Siamagka

Henley Business School

University of Reading

E:nikoletta.siamagka@henley.reading.ac.uk

\author{
George Christodoulides ${ }^{1}$ \\ Department of Marketing \\ The Birmingham Business School \\ University of Birmingham \\ E: G.Christodoulides@bham.ac.uk
}

T: 01214148318

\section{Authors' biographies}

${ }^{1}$ Corresponding Author 
Nina Michaelidou is a Senior Lecturer in Marketing at the Birmingham Business School, University of Birmingham. Her research interests encompass consumer involvement, variety seeking and social media usage. She is the leader of the Academy of Marketing Special Interest Group on Consumer Research, and has published papers in various journals including Journal of Marketing Management, European Journal of Marketing, Journal of Strategic Marketing, Journal of Business Research and Journal of Consumer Affairs.

Nikoletta Theofania Siamagka (Ph.D., University of Birmingham) is a Lecturer in Marketing at Henley Business School, University of Reading. Her main research interests include emarketing, consumer ethnocentrism and product placement.

George Christodoulides is a Senior Lecturer in Marketing at the University of Birmingham. His research focuses on brand management and e-marketing, and has appeared in journals such as the Journal of Advertising Research, Industrial Marketing Management and the European Journal of Marketing. George’s research has been sponsored by prestigious external funding bodies including the Economic and Social Research Council, the British Academy and the Chartered Institute of Marketing. 


\section{Research Highlights}

$>$ We examine the social networking practices by B2B SMEs >We find that B2B SMEs using social networking sites in the UK do so mostly to attract new customers. $>$ Almost half of the B2B SEMs using social networking sites indicate their intention to increase marketing spending on social networking sites. < B2B SME's not using social networking sites due to the lack of perceived relevance of social networking sites for particular industry sectors. 


\begin{abstract}
Previous research has established the benefits of branding for business-to-business (B2B) organizations. Various tools can be used to support B2B brands, including the internet and other interactive technologies. Yet research on how organizations use Social Networking Sites (SNS) to achieve brand objectives remains limited. This study addresses the gap by focusing on B2B SMEs and their social networking practices, particularly, usage, perceived barriers, and the measurement of effectiveness of SNS as a marketing tool. Findings from a mail survey show that over a quarter of B2B SMEs in the UK are currently using SNS to achieve brand objectives, the most popular of which is to attract new customers. On the other hand, the most significant barrier is the lack of perceived relevance for particular sectors. Notably, the overwhelming majority of users do not adopt any metrics to assess SNS effectiveness. Almost half of the sample of SMEs that currently use SNS have indicated their intention to increase their marketing spending on this channel, highlighting the growing importance of SNS in a B2B context.
\end{abstract}

Keywords: Social Media, Social Networking Sites, B2B brands, SMEs 


\section{Introduction}

The advent of Web 2.0 has created new ways to communicate, collaborate and share content (Enders, Hungenberg, Denker, \& Mauch 2008). Statistics from NielsenWire (2010) show that in 2009, social media and specifically, social networking sites (SNS) such as such as Facebook, Twitter, MySpace and LinkedIn, were a popular online activity in terms of average time spent. Currently, there are more than 150 SNS; in 2009, Facebook was ranked first in terms of popularity, with 206.9 million unique visitors globally (NielsenWire 2010).

Social media, also known as ‘user-generated communication’, now represents a prevalent source of information; it has changed the tools and strategies companies use to communicate, highlighting that information control now lies with the customer (Mangold \& Faulds 2009). A study by Cone (2008) (http://www.coneinc.com/) shows that $93 \%$ of social media users believe that companies should have a social media presence, while $85 \%$ of them think that companies should interact with customers via SNS. Companies have now penetrated the online social networking scene, offering direct links from their corporate websites to Facebook and Twitter, and use these tools to promote brands and support the creation of brand communities (Kaplan \& Haenlein 2010). Recent statistics show that advertising spending on Facebook and MySpace is expected to reach $\$ 605 \mathrm{~m}$ and $\$ 435 \mathrm{~m}$ respectively for 2010, whilst a significant portion of this spending will go towards building and maintaining a social network presence (Williamson 2009).

Despite the popularity of SNS, their importance in shaping commercial online interaction (Mislove et al. 2007) and their potential to support brands (Christodoulides 2009), research into SNS is very limited, and focuses largely on the consumer in a B2C domain. To date, there is paucity of systematic research on how SNS are used by companies, particularly B2B 
companies, and how they contribute to brand objectives. Anecdotal evidence (e.g. Shih 2009) suggests that social media is important for $\mathrm{B} 2 \mathrm{~B}$ companies. B2B companies can use social media and specifically SNS such as Facebook and LinkedIn to communicate with their customers and suppliers, build relationships and trust, as well as to identify prospective partners in terms of B2B selling (Shih 2009). It is notable that while B2B e-commerce is valued at more than three and half times that of B2C e-commerce (Kalapesi, Willesdof \& Zwillenberg 2010) the interest in, and subsequent adoption of, social media by B2B organizations has been slow compared to their B2C counterparts.

This lack of research into SNS in a B2B environment provides the impetus for our studywhich addresses this gap, and contributes to existing literature in the following ways. First, it examines how B2B SMEs use SNS. Our decision to focus on small and medium sized companies within a B2B context is because they represent the majority of industrial businesses, and are a significant driver of economic growth (LaPlaca 2011). Second, the study provides insights into the extent of use and the reasons why B2B SMEs use SNS, as well as insights into the perceived barriers that inhibit usage. Third, it examines differences between organizations from different industries in terms of their usage of SNS. Fourth, the study explores the measurement practices used by companies who engage in brand activities on SNS. Despite calls from both industry and academia for new and creative metrics to suit the social media environment (Russell 2009), very little is known as to the metrics actually used by B2B organizations to assess their branding efforts on SNS. Fifth, it investigates whether there are differences between users and non-users of SNS, based on their organizational innovativeness levels. 
The paper opens by reviewing the literature on B2B branding and social media. It then discusses the methodology and main findings of a postal survey administered to a sample of B2B SMEs in the UK. The findings are discussed in the light of the previous literature highlighting implications for practitioners and suggestions are made for further research.

\section{Background}

\subsection{B2B Branding and the Internet}

Previous research has established the importance of branding for B2B firms (e.g. Mudambi 2002; Lynch \& de Chernatony 2004; Leek \& Christodoulides 2010; Lindgreen, Beverland \& Farrelly 2010). In an age characterized by increasing commoditization (van Riel et al. 2005), branding allows B2B organizations to differentiate by creating a unique and consistent identity (Mitchell, King \& Reast 2001). A strong B2B brand results in enhanced quality perceptions in the market (Cretu \& Brodie 2007) and allows organizations to transfer brand equity in other categories through extensions (Hutton 1997). It raises the barriers to entry for competitive brands and leads to higher demand and/or allows companies to command a premium price (Mitchell et al. 2001; Low \& Bois 2002; Ohnnemus 2009). In competitive bidding situations, which are often the norm in industrial markets, a branded product may help achieve consensus in the decision making unit, and influence the decision in favor of the owning brand (Wise \& Zendnickova 2009). In the distribution channel, a strong B2B brand increases the company's negotiating power, and opens up opportunities for licensing (Low \& Bois, 2002; Ohnemus 2009). Finally, a strong B2B brand is more likely to enjoy higher loyalty (McQuiston 2004) and more referrals from buyers (Bendixen, Bukasa \& Abratt 2004). 
Following the advent of the internet, business marketing companies have started to appreciate this tool as a value-adding channel that enables companies to provide information, to accommodate connectivity, community and transactions, and to share cost reductions (Sharma 2002). According to Pitt et al. (2006: 600) “...the internet is becoming the most important vehicle for global business-to-business commerce”. B2B marketers thus use the internet to generate value for their brands through information, knowledge, conversations, relationships and e-commerce (Sharma 2002). Along similar lines to Sharma (2002), Walters (2008) advocates three value-adding strategies when using the internet, namely information rich strategy, relational exchange, and joint learning strategy. Bauer, Grether and Leach (2002) focus solely on the significant role of the internet in building customer relationships in a B2B context. By examining the impact of specific internet characteristics (e.g. interactivity and information availability) on key relational variables (e.g. trust, satisfaction and commitment) the authors underline the suitability of the internet as a relationship marketing channel.

\subsection{Social Networks, Social Media and SNS}

Social networks originate from sociology and, in a business context, refer to two or more connected business relationships, where an 'exchange' exists between business partners (Anderson, Hakansson, \& Johanson 1994; Pitt et al. 2006). The notion of a 'network' is based on the establishment of ties between individuals, groups of people, organizational departments or corporations, that leads to the creation of social networks (Wasserman \& Faust 1994). Social networks differ with respect to their size and heterogeneity (Garton, Haythornthwaite \& Wellman 1997). Smaller, homogenous networks can be found in work groups (Lea et al. 2006), while larger, more heterogeneous networks are typically more complex and are associated with more diverse social characteristics. 
In general, social networks are beneficial and valuable for the network participants in that they promote activities and the use of resources (Gamunden, Ritter \& Walter 1997). Within a commercial context, social networks offer significant benefits, including the enhancement of economic value for organizations (Stephen \& Toubia, 2010). A number of studies have used social networking theory to study the social networks of firms in B2B environments (e.g. Björkman \& Kock 1995). Further, Pitt et al. (2006) and McCarthy et al. (2007) used social network theory to examine internet links between B2B firms. Social networks are important for the survival of small firms, and critical in competing with larger businesses (Pitt et al. 2006; Copp \& Ivy, 2001).

Technological progress and innovation have altered the nature of social networks. In particular, while traditional social networks have involved personal interactions of humans over time (Kimball \& Rheingold 2000), interactions are now mediated by computers, which suggests a more impersonal form of communication. These computer-mediated networks or online social networks are more complex, and involve a greater degree of heterogeneity. Yet, the benefits associated with social networks are enhanced in an online environment, where the problems of time and geographical location become less significant. Members of an online network can exchange information and provide solutions from and to different locations across the world in a very short period of time (Lea et al. 2006).

Given the importance of social networks and the internet (e.g. Sharma 2002; Walters 2008), which facilitate direct unmediated inter-organizational associations (Berthon et al. 2003; Pitt et al. 2006), it is argued that social media, and particularly SNS, can support brands, including B2B brands by developing and maintaining relationships between B2B firms. 
According to Mangold and Faulds (2009), social media consists of new sources of online information such as SNS, blogs, chat-rooms, rating websites, video and photo sharing websites and podcasts, created and used for educational purposes about issues including products and brands. In particular, SNS such as Facebook are some of the most popular and frequently visited web sites in the world (alexa.com) and, as such, marketers have intuitively recognized their potential in helping to achieve brand objectives (van den Bulte \& Wuyts 2007). Social media are becoming more important as an internet marketing tool given their wide adoption by the general public. Evidence suggests that in consumer markets, SNS have become “de facto modus operandi” (Mangold \& Faulds 2009: 359) for users to disseminate information about brands.

However, research into social media, and specifically SNS, is still at an embryonic stage, and interest is focused mostly on a B2C context. In particular, previous academic research with regard to SNS has examined privacy and ethical issues, the prevalence of SNS among groups (e.g. students, professionals), and the motivations for usage (Dwyer, Hiltz \& Passerini 2007; DiMicco et al. 2008; Pempek, Yermolayeva \& Calvert 2009; Clark \& Roberts, 2010). Other research has examined how SNS generates word-of-mouth (WOM) in comparison with traditional marketing vehicles (Trusov, Bucklin \& Koen 2009), how they generate revenue (Enders et al. 2008) and how they can serve as shopping channels (Cha 2009). Despite the aforementioned benefits, B2B organizations seem to have realized SNS potential in supporting their brands later than B2C organizations. A time-line based on Google trends shows a growing interest in social media since 2004, while specific interest in social media in B2B only emerged in 2010.

Place Figure 1 Here 


\subsection{Benefits and Barriers of Social Media}

Anecdotal evidence from market research reports suggests that firms use social media, including SNS, inter alia, to build direct relationships with customers, increase traffic to their website, identify new business opportunities, create communities, distribute content, collect feedback from customers, and generally to support their brand (Breslauer \& Smith 2009; eMarketer 2010). Indeed, due to their non-transactional nature, SNS are particularly suited for collecting information/feedback from customers, initiating two-way conversations with customers and developing relationships with customers through communication and interaction (Enders et al. 2008; Kaplan \& Haenlein 2010).

Additionally, one must consider that being a new technology, SNS may not be particularly attractive to B2B companies. Previous literature highlights barriers, both internal and external, to the adoption of new technologies by B2B organizations (Buehrer, Senecal \& Bolman Pullins 2005). Indeed many organizations have been slow to adopt new technologies due to perceived barriers such as lack of money, time and training, negative views about usefulness, as well as unfamiliarity with the particular technology (Buehrer et al. 2005; Venkatesh \& Davis 2000). Adoption of an innovation is therefore based on the perceptions of organizations regarding the particular technology, which ultimately determines the time of adoption (Dillon \& Morris 1996; Iacovou, Benbasat \& Dexter 1995).

In addition, the adoption of technologies such as the internet also depends, inter alia, on the innovativeness of the specific organization as well as the personal innovativeness of the CEO (Gauvin \& Sinha 1993; Thong \& Yap 1995; Agarwal \& Prasad 1998; Premkumar \& Roberts 
1999; Mehrtens, Cragg \& Mills 2001; Lu, Yao \& Yu 2005). Similarly, Frambach and Schillewaert (2002), suggest that organizational innovativeness as well as firm size determine the adoption decision. Frambach and Schillewaert further suggest that smaller firms are more innovative, and are therefore expected to be more receptive to new technologies. On this basis, more innovative small and medium B2B companies are expected to be early adopters of SNS.

\subsection{Social Media Metrics}

As with every marketing tool, SNS need to be evaluated for their effectiveness in achieving brand-related objectives. In an era characterized by increasing transparency and accountability (McDonald \& Mouncey 2009) and decreasing marketing budgets, the development of the right metrics is paramount for marketers, who are under immense pressure to show results for their spending. Traditional marketing metrics (for a summary see Ambler 2003) are based on a linear form of communication, and do not suit the interactivity of Web 2.0 (Hoffman \& Novak 1996). The literature suggests that the measurement of such networks pose significant problems for marketing managers, who need to evidence the results of their spending. The measurement problem is highlighted in existing studies, with Borders, Johnston and Rigdon (2001) suggesting that,

“...existing business metrics were designed for a world of concrete boundaries and fixed categories - a world that is slipping away day by day... The same phenomenon will plague the business economy, as networks become more influential while remaining temporary and informal. On the other hand, perhaps this change will finally force researchers to develop metrics that are truly customer-centric, instead of relying on categories of business organizations as a convenient crutch.” (p.204). 


\section{Method}

Data was collected from a sample of 1,000 UK B2B SMEs, randomly derived from the $\mathrm{FAME}^{2}$ database via a mailed questionnaire. The questionnaire was sent to the marketing director or general director of each B2B SME, and a completion incentive was offered in the form of providing a summary of the study's results. Companies targeted derived from various industrial sectors (e.g. manufacturing, agriculture, etc.) and varied in terms of employee numbers from 1 to 250, with a turnover below 50 million Euros, in line the EU definition of small and medium enterprises (European Commission 2003). One hundred and forty-six questionnaires were returned with 102 being fully completed, representing a response rate of 15\% (effective response rate 10.2\%). Ten companies were excluded from the sample as they did not conform to the definition of SMEs. The questionnaire consisted of four parts, and included measures based on the previous literature (e.g., Buehrer et al. 2005), to capture the extent of usage of SNS by SMEs, barriers and benefits of usage, as well as questions about metrics used to evaluate the effectiveness of SNS in supporting brand objectives. Finally, three items were used to capture organizational innovativeness based on previous research (Garcia-Morales, Llorens-Montes \& Verdu-Jover 2006).

\section{Analysis and Findings}

Initial statistics show that the average number of employees in SMEs in the sample was 66, and the average sales turnover was between $£ 1$ and $£ 10$ million. Respondents had held their positions in the companies concerned for an average of 9 years. Table 1 shows the companies’ characteristics.

\footnotetext{
${ }^{2}$ FAME is a business database which contains information on companies in the UK. Fame can be used to research individual companies and to search for and analyze companies with specific profiles (e.g. SMEs).
} 
Analysis of the data was conducted to explore usage or non-usage of SNS, as well as to uncover the perceived benefits of using SNS and the perceived barriers. Chi-square tests were also conducted to identify any differences among B2B companies in terms of usage, based on industry, small/medium size, and sales turnover. The results are presented below and are organized by users/non-users of SNS.

\subsection{SNS Users}

The findings indicate that $27 \%$ of the B2B SMEs included in the sample used SNS. The majority of those SMEs used Facebook (77\%) as a platform to meet their targets. The data shows that those using social networks had a presence on more than one site (Table 2). Fifty percent of the companies were either not investing any financial resources from their marketing budgets to SNS, or they were only using one percent of their budgets for this purpose.

Place Table 2 Here

In addition, none of the companies included in the sample planned to decrease their investments in SNS, whilst 44\% considered increasing the budget allocated to SNS. Table 3 summarizes the main reasons why companies use SNS. The majority of companies that use SNS were doing so to attract new customers (91\%), to cultivate relationships with their audience (86\%), to increase awareness of their brand (82\%) or to communicate the brand 
online (73\%). Receiving feedback (46\%) and interacting with suppliers (14\%) were found to be less popular reasons for using SNS.

Place Table 3 Here

Companies using SNS tend not to evaluate their effectiveness in supporting their brands (53\%). Respondents seem to mildly agree that their lack of knowledge with respect to possible metrics was one of the reasons why they failed to investigate SNS' effectiveness $(M=2.81 \mathrm{sd}=1.47)$. Yet, more than half of them claimed that they are considering evaluating SNS effectiveness in the near future (61\%). The vast majority of those measuring SNS effectiveness were doing so predominantly based on the number of users joining their group (73\%). The number of comments (irrespective of their nature) also prevailed as an important metric to evaluate SNS effectiveness (55\%). Notably, friends' requests were among the least popular indicators amongst managers of B2B SMEs (46\% were using friends’ requests). Table 4 presents the most significant measures of SNS effectiveness used by companies.

Place Table 4 Here

\subsection{SNS Non-Users}

On the other hand, 73\% of B2B SMEs indicated that they were not using SNS to support their brand strategies. The majority of respondents supported the view that SNS are not important for their industries (61\%), while 44\% were unsure as to whether or how SNS could help their brands. Unfamiliarity on the part of staff, limited staff technical skills and increased investment in terms of time, indicated that the participating firms lacked the necessary 
experience, expertise and resources to adopt SNS. This makes SMEs less confident about using this channel to achieve marketing objectives. Finally, as in every competitive situation, competitors' current practices and their decision not to use SNS also constituted a significant barrier to SNS adoption. Table 5 summarizes the main barriers perceived by the respondents.

\section{Place Table 5 Here}

Chi-square tests were also conducted to uncover any differences among the companies in terms of usage of SNS based on industry membership and employee numbers. Interestingly, no differences were observed between companies operating in the services and goods industries with respect to their usage of SNS $\left(\chi^{2}=1.13, \mathrm{p}>.005\right)$. Similarly, no differences were found in terms of usage based on the SME's sales turnover $\left(\chi^{2}=2.13, p>.005\right)$ and between small and medium sized businesses $\left(\chi^{2}=.68, \mathrm{p}>.005\right)$. Thus, results highlight thefact that SMEs' use of SNS does not differ with respect to a specific B2B industry, small/medium size and sales turnover.

Finally, a t-test was performed in order to investigate differences between users and nonusers of SNS based on organizational innovativeness. Reliability for the innovativeness scale was acceptable; $\alpha=.83$. The results indicate significant differences in terms of organizational innovativeness between SNS users $(M=2.46$, sd=0.71) and non-users ( $M=3.1, \mathrm{sd}=1.34)$; $\mathrm{t}$ $(88)=2.94, \mathrm{p}<.005)$. 


\section{Discussion}

Our study contributes to the paucity of research on the usage, barriers and measurement of social media marketing by B2B SMEs. The findings from our postal survey indicate that over a quarter of B2B SMEs in the UK are currently using SNS to achieve their marketing objectives. This is an interesting finding given the fact that SNS have received no attention to date in the academic B2B literature. Also, none of the firms in the sample, plan to decrease their budgets with regard to SNS, while 44 percent of firms plan to increase their spending on SNS in the following year, suggesting an emerging "legitimacy" of social media as a marketing tool in a B2B context.

B2B SMEs using SNS have recognized the importance of this tool to support marketing outcomes (van den Bulte \&Wuyts 2007). In contrast to a B2C context, where awareness is the most prominent reason for adopting SNS (eMarketer 2010), awareness comes third in importance for B2B SMEs. Attracting new customers and cultivating customer relationships are considered to be the most important goals for such organizations when using SNS. This finding highlights the important role of relationship marketing in a B2B setting, and is aligned with past evidence suggesting that the internet and technology could be used as tools to build relationships (Sharma 2002; Bauer et al. 2002). In addition, considering that branding is a valuable differentiation strategy, not only for B2C but also B2B organizations (Mitchell et al. 2001), managers should strive to establish brand awareness as a first step towards making their brand stand out from that of the competition. Through SNS, B2B firms can capitalize on pre-existing business networks to achieve word of mouth and to make their brands better known. This justifies the increased importance of awareness as a reason for using SNS. To achieve a stronger competitive advantage, B2B SMEs indicate that SNS are important tools for communicating their brands online by capitalizing on SNS' potential to 
reach wide audiences. Along similar lines to the internet, B2B SMEs could also benefit from the use of SNS by their joint learning nature and the feedback provided through this channel (e.g. Walters 2008; Sharma 2002).

Furthermore, the main reason for firms' reluctance to use SNS is the nature of the industries these firms operate in, and the perceived irrelevance of SNS within that context. Although results indicate that usage patterns do not differ based on the industry SMEs operate in, relevance perceptions with respect to industries prevail as a significant external barrier to SNS usage. Consistent with the extant literature, where lack of training and management/technical support were established as significant barriers to using technology (del Aguila-Obra \& Padilla-Meléndez 2006; Buehrer et al. 2005), our findings also highlight internal barriers such as lack of staff familiarity and technical skills as factors that prevent SMEs from using SNS to support their brands. This is also in line with Rogers (1983), who argues that complexity is one of the five general attributes that influence adoption. In addition, our findings provide further support to the importance of cost (in this case in terms of time) as a barrier to SNS usage (e.g. Buehrer et al. 2005; Tornatzky \& Klein 1982).

Consistent with previous literature on the adoption of technologies (e.g., Mehrtens et al. 2001; Frambach \& Schillewaert 2002), the adoption of SNS by SMEs is also determined by the innovativeness of the specific organization. More innovative companies are more likely to use SNS, a finding which is probably linked to the early stages of interest for SNS in a B2B context (see, for example Figures 1 \& 2).

In addition, the findings of this study illustrate that SNS users fail to satisfy the need for more creative metrics (Russell 2009). Despite the increased pressure for marketing managers to 
provide evidence of the effectiveness of their marketing activities, the vast majority of SNS users are not evaluating the effectiveness of their SNS in supporting their brands.

Consequently, marketing managers are not able to provide quantified data that illustrate the importance of SNS, which might explain the reason why professionals remain skeptical about SNS as an effective marketing tool. Yet, the increased influence of social networks (e.g., customer reviews/feedback) might force organizations to develop more customer-centered metrics to evaluate SNS effectiveness (Borders et al. 2001). In fact, the number of users joining the groups created by the B2B SMEs, and the discussions as well as the number of comments made, constitute the most popular measurement tools. This comes in agreement with the significant role of feedback as a driver towards SNS use (Sharma 2002; Walters 2008). The list of metrics used by B2B SMEs is in line with the extant literature that discusses possible effectiveness indicators (e.g. Berkowitz 2009 in Sterne 2010). Interestingly, although attracting new customers prevailed as the most important reason for using SNS, the importance of the number of customers attracted via SNS as a measurement tool is relatively low, coming only fourth amongst the most popular metrics. This finding illustrates that there is inconsistency between the goals of SNS use and the metrics used to assess whether or not these goals have been satisfied.

Finally, despite evidence suggesting that firm size is positively related to the use of technology (del Aguila-Obra \& Padilla-Meléndez 2006; Premkumar \& Roberts 1999), findings from this study illustrate that the usage of SNS does not differ in terms of firm size. A possible explanation for the lack of a significant relationship between firm size and the usage of SNS is the cost effectiveness of SNS, and the relatively limited financial resources required for their adoption. Consequently, even small or medium sized B2B organizations could invest in SNS to embrace their brand objectives. The lack of a relationship between 
size and usage could also be attributed to the focus of this study, which is on B2B SMEs; differences might be observed when SMEs are compared with larger B2B organizations.

\section{Conclusion}

There is dearth of literature focusing on how B2B companies use SNS. This study contributes to knowledge by exploring the barriers, usage and perceived benefits of SNS among B2B SMEs in the UK, and reveals some interesting findings. Specifically, the study sheds light on the barriers with regard to the use of SNS which include the perceived irrelevance of SNS within the industry the company operates in, uncertainty as to the use of SNS to support brands, as well as barriers such as staff familiarity and lack of training. The finding highlights the varied managerial mindsets regarding the usage of SNS to support brands across B2B SMEs, irrespective of industry, and this has implications for the adoption of SNS and generally social media by B2B firms. In contrast to other technologies (e.g. e-commerce), SNS do not require a large investment. However, their diffusion among B2B SMEs is ostensibly slow, with the majority of B2B SMEs in the UK being uncertain as to how SNS can be used to support their brands.

Additionally, the study shows that over a quarter of B2B SMEs have recognized the importance of SNS in supporting brands (van den Bulte \& Wuyts 2007) and are therefore using SNS primarily to attract customers and to cultivate customer relationships. Additional perceived benefits stemming from the use of SNS include increasing awareness and communicating the brand online. This finding has implications for the use of SNS in customer relationship management. Following from evidence highlighting the important role of branding in a B2B setting, B2B firms can use SNS to create customer value in the form of interacting with customers, as well as building and fostering customer relationships. Being 
closer to their customers will enable them to create a unique brand identity and to differentiate themselves from the competition. Customers can also benefit from the company in that through the use of SNS, they will be able to communicate with the company and provide feedback.

\section{Limitations and Future Research}

The study highlights the limited extent of metrics used by B2B SMEs to evaluate the effectiveness of SNS. However, it does not provide a full account of the reasons why B2B SMEs are not assessing SNS effectiveness. Future research should therefore focus on enhancing knowledge with respect to the reasons why the majority of SNS users are not assessing the effectiveness of their sites.

In addition, evidence suggests that attitudes to technology affect adoption (e.g. Ha and Stoel 2009). However, this study did not provide insights into the attitudes of SMEs towards technology and, in particular, SNS. Future research should focus on establishing the link between attitudes towards technology and the intention to adopt or actual adoption behavior.

Our study could also stimulate future research, focusing on the use of SNS by B2B customers. Our research highlights that the most prominent reason for the use of SNS by B2B SMEs is to attract new customers. Consequently, it would be useful to investigate whether SNS satisfy this objective by addressing this issue from the buyer's point of view. Finally, this study could be replicated with a sample of large B2B companies to investigate whether adoption rates, usage, barriers and metrics strategies are the same as those relating to smaller B2B companies. 
This study's findings indicate that perceived SNS irrelevance within certain industries is an important barrier to SNS use. Considering that SNS may be more relevant to certain industries than others, future research might focus on adoption times, and might investigate the impact of industry type on how quickly B2B firms adopt SNS. For example, it is expected that IT B2B organizations will be early adopters, and therefore might have had an established presence in SNS for a relatively longer time than organizations operating in other industries (e.g. office supplies). An investigation of the relationship between adoption time and reasons for adoption would also provide valuable insight into the factors that encourage organizations to be early adopters of SNS. 


\section{References}

Agarwal, R. \& Prasad, J. (1998). A Conceptual and operational definition of personal innovativeness in the domain of information technology. Information Systems Research, 9 (2), 204-215.

Ambler, T. (2003). Marketing and the bottom line: Creating the measures of success. $\left(2^{\text {nd }}\right.$ ed.) London: Financial Times/Prentice Hall.

Anderson, J. C., Hokansson, H. \& Johanson, J. (1994). Dyadic business relationships within a business network context. Journal of Marketing, 58, 1-16.

Bauer, H. H., Grether, M. \& Leach, M. (2002). Building customer relations over the internet. Industrial Marketing Management, 31, 155-163.

Buehrer, R. E., Senecal, S. \& Bolman Pullins, E. (2005). Sales force technology usagereasons, barriers, and support: An exploratory investigation. Industrial Marketing Management, 34, 389- 398.

Bendixen, M., Bukasa, K. A. \& Abratt, R. (2004). Brand equity in the business-to-business market. Industrial Marketing Management, 33, 371-380.

Berthon, P., Ewing' M., Pitt, L. P. \& Naudé, P. (2003). Understanding B2B and the Web: the acceleration of coordination and motivation. Industrial Marketing Management, 32 (7), 553556. 
Björkman I. \& Kock, S. (1995). Social relationships and business networks: The case of Western companies in China. International Business Review, 4 (4), 519-535.

Breslauer, B. \& Smith, T. (2009). Social media trends around the world! The global web index (GWI). ESOMAR Research, Online Research, Chicago.

Borders, A. L., Johnston, W. J. \& Rigdon, E. E. (2001). Beyond the dyad: electronic commerce and network perspectives in industrial marketing management. Industrial Marketing Management, 30, 199-205.

Cha, J. (2009). Shopping on social networking web sites: attitudes towards real versus virtual items. Journal of Interactive Advertising, 10 (1), 77-93.

Christodoulides, G. (2009). Branding in the post-internet era. Marketing Theory, 9 (1), 141144.

Clark, L. A. \& Roberts, S. J. (2010). Employer's use of social networking sites. Journal of Business Ethics, 95, 507-525.

Cone (2008). Business in social media study. (http://onesocialmedia.com/wpcontent/uploads/2010/03/2008_business_in_social_media_fact_sheet.pdf).

Copp, C. B., \& Ivy, R. I. (2001). Networking trends of small tourism businesses in postsocialist Slovakia. Journal of Small Business Management, 39 (4), 345-353.

Cretu, A. E. \& Brodie, R. J. (2007). The influence of brand image and company reputation where manufacturers market to small firms: a customer value perspective. Industrial Marketing Management, 36, 230-240.

Del Agiula-Obra, A. R. \& Padilla-Meléndez, A. (2006). Organizational factors affecting Internet technology adoption. Internet Research, 16 (1), 94-110. 
Dillon, A. \& Morris, M. (1996) User acceptance of information technology: theories and models. In: M. Williams (ed.), ARIST, Vol. 31, (M. Williams, ed.), Medford, NJ: Information Today.

DiMicco, J., Millen, D. R., Geyer, W., Gugan, C., Brownholtz, B. \& Muller, M. (2008). Motivations for social networking at work. Proceedings of the 2008, IBM Conference, Cambridge, Massachusetts.

Dwyer, C., Hiltz, S. \& Passerini, K. (2007). Trust and privacy concern within social networking sites: a comparison of Facebook and MySpace. Americas Conference on Information Systems (AMCIS), AMCIS 2007 Proceedings, Association for Information Systems.

e-Marketer (2010). Leveraging best practices for social media, November 23 2010. Available at http://www.emarketer.com/Article.aspx?R=1008057 [Accessed 23 November 2010].

Enders, A., Hungenberg, H., Denker, H-P, \& Mauch, S. (2008). The long tail of social networking: revenue models of social networking sites. European Management Journal, 26, 199-211.

European Commission (2003). The new SME definition: User guide and model declaration. Enterprise and Industry publications. European Commission.

http://ec.europa.eu/enterprise/policies/sme/files/sme_definition/sme_user_guide_en.pdf Frambach, R.T. \& Schillewaert, N. (2002). Organizational innovation adoption: a multi-level framework of determinants and opportunities for future research. Journal of Business Research, 55 (2), 163-176. 
Garcia-Morales, V., Llorens-Montes, F. J. \& Vertu-Jover, A. J. (2006). Antecedents and consequences of organizational innovation and organizational learning in entrepreneurship Industrial Management \& Data Systems, 106 (1), 21-42.

Garton, L., Haythornthwaite, C., \& Wellman, B. (1997). Studying online social networks. Journal of Computer-Mediated Communication, 3 (1),

Available at: http://jcmc.indiana.edu/vol3/issue1/garton.html [Accessed 01/07/2011]

Gauvin S. \& Sinha R.K. (1993). Innovativeness in industrial organizations : A two-stage Model of ddoption. International Journal of Research in Marketing, 10, 165.183.

Ha, S. \& Stoel, L. (2009). Consumer e-shopping acceptance: Antecedents in a technology acceptance model, Journal of Business Research, 62 (5), 565-571.

Hoffman, D. L. \& Novak, T. P. (1996). Marketing in hypermedia computer mediated environments: conceptual foundations, Journal of Marketing 60 (3), 50-68.

Hutton, J. G. (1997). A study of brand equity in an organizational-buying context. Journal of Product and Brand Management, 6 (6), 428-439.

Iacovou, C. L., Benbasat, I. \& Dexter, A. S. (1995). Electronic data interchange and small organizations: Adoption and impact of technology. MIS Quarterly 19 (4), 465-485.

Kalapesi, C., Willersdorf, S. \& Zwillenberg, P. (2010). The connected Kingdom: How the internet is transforming the UK economy. BCG report, Boston, MA.

Kaplan, A. M., \& Haenlein, M. (2010). Users of the world, unite! The challenges and opportunities of social media. Business Horizons, 53 (1), 59-68. 
Kimball, L. \& Rheingold, H. (2000). How online social networks benefit organizations. Rheingold Associates, CA: Poplar Mill Valley.

LaPlaca, P. (2011). Letter from the editor: Special issue on industrial marketing strategy and B2B management by SMEs. Industrial Marketing Management, 40 (3) 331-333.

Lea, B.R., Wu, W.B., Maguluru, N., \& Nichols, M. (2006). Enhancing business networks using social network based virtual communities. Industrial Management \& Data Systems, 106 (1), 121-138.

Leek, S. \& Christodoulides, G. (2010). A literature review and future agenda for B2B branding. IMP Conference, Budapest.

Lindgreen A., Beverland, M. B. \& Farrelly, F. (2010). From strategy to tactics: Building, implementing, and managing brand equity in business markets. Industrial Marketing Management, 39, 1223-1225.

Lu, J., Yao, E. J. \& Yu, C-S. (2005). Personal innovativeness, social influences and adoption of wireless Internet services via mobile technology. Journal of Strategic Information Systems, 14 (3), 245-268.

Lynch, J. \& de Chernatony, L. (2004). The Power of emotion: Brand communication in business-to business markets. Brand Management, 11 (5), 403-419.

Mangold, W. G. \& Faulds, D. J. (2009). Social media: The new hybrid element of the promotion mix. Business Horizons, 52, 357-365.

Mahrtens, J., Cragg, P. B. \& Mills, A. M. (2001). A model of internet adoption by SMEs. Information \& Management, 39 (3), 165-176. 
McDonald, M. \& Mouncey, P. (2009). Marketing accountability: How to measure marketing effectiveness, London: Kogan.

McCarthy, I. P., Pitt, L., Campell, C., van der Merwe, R. \& Salehi-Sangeri, E. (2007).

Exploiting the business opportunities in biotech connections: The power of social networks. Journal of Commercial Biotechnology, 13, 245-257.

McQuiston, D. H. (2004). Successful branding of a commodity product: The case of RAEX laser steel. Industrial Marketing Management, 33, 345-354.

Mislove, A., Marcon, M., Gummadi, K.P., Druschel, P., \& Bhattacharjee, B. (2007).

Measurement and analysis of online social networks. Proceedings of the 2007 IMC, San Diego California.

Mitchell, P., King, J. \& Reast, J. (2001). Brand values related to industrial products. Industrial Marketing Management, 30, 415-425.

Mudambi, S. (2002). Branding importance in business-to-business markets three buyer clusters. Industrial Marketing Management, 31, 525-533.

NielsenWire (2010). Led by Facebook, Twitter, global time spent on social media sites up 82\% Yyar over year, January 22 2010. Available at: http://blog.nielsen.com/nielsenwire/global/led-by-facebook-twitter-global-time-spent-onsocial-media-sites-up-82-year-over-year/ [Accessed 26 November 2010].

Ohnemus, L. (2009). B2B branding: A financial burden for shareholders? Business Horizons, 52, 159-166. 
Pempek, T.A., Yermolayeva, Y.A., \& Calvert, S.L. (2009). College students’ social networking experiences on Facebook. Journal of Applied Developmental Psychology, 30, 227-238.

Pitt, L., van der Merwe, R., Berthon, P., Salehi-Sangari, E. \& Caruana, A. (2006). Global alliance networks: A comparison of biotech SMEs in Sweden and Australia. Industrial Marketing Management, 35, 600-610.

Premkumar, G. \& Roberts, M. (1999). Adoption of new information technologies in rural small businesses. Omega, 27 (4), 467-484

Rogers, E.M. (1983). Diffusion of innovations. New York: The Free Press.

Russell, M.G. (2009). A call for creativity in new metrics for liquid media. Journal of Interactive Advertising, 9 (2), 44-61.

Thong, J. Y. L. \& Yap, C. S. 1995. CEO characteristics, organizational characteristics and information technology adoption in small businesses. Omega, 23 (4), 429-422.

Tornatzky, L. G. \& Klein, K. J. (1982). Innovation characteristics and innovation adoptionimplementation: A meta-analysis of findings. IEEE Transactions on Engineering Management, 29 (1), 28-43

Trusov, M., Bucklin, R. E., \& Koen, P. (2009). Effects of word-of-mouth versus traditional marketing: Findings from an internet social networking site. Journal of Marketing, 73, 90Sharma, A. (2002). Trends in internet-based business-to-business marketing. Industrial Marketing Management, 31, 77-84.

Shih, C. (2009). The Facebook Era: Tapping Online Social Networks to Build Better Products, Reach New Audiences, and Sell More Stuff. Prentice Hall, Boston MA. 
Stephen, A.T. \& Toubia, O. (2010). Deriving value from social commerce networks. Journal of Marketing Research, 47 (2), 215-228.

Sterne, J. (2010). Social Media Metrics: How to measure and optimize your marketing investment. John Wiley and Sons, New Jersey.

Walters, P. G. P. (2008). Adding value in global B2B supply chains: strategic directions and the role of the internet as a driver of competitive advantage. Industrial Marketing Management, 37, 59-68.

Wise, R. \& Zednickova, J. (2009). The rise and rise of the B2B brand. Journal of Business Strategy, 30 (1), 4-13.

Van Den Bulte, C. \& Wuyts, S. (2007). Social networks and Marketing. Marketing Science Institute, MA: Cambridge.

Van Riel, A.C.R., de Mortanges, C. P., \& Streukens, S. (2005). Marketing antecedents of industrial brand equity: An empirical investigation in specialty chemicals. Industrial Marketing Management, 34, 841-847.

Venkatesh, V. \& Davis, F.D. (2000). A theoretical extension of the technology acceptance model: Four longitudinal field studies. Management Science, 46 (2), 186-204.

Wasserman, S., \& Faust, K. (1994). Social network analysis: Methods and applications. Cambridge: Cambridge University Press.

Williamson, D. (2009). Social network ad spending: 2010 outlook. e-Marketer, December 2009. 
Table 1 B2B SMEs Characteristics

\begin{tabular}{ll}
\hline B2B SMEs Characteristics & N (\%)* \\
\hline Industry & $28(35)$ \\
Goods & $53(65)$ \\
Services & \\
Size (Sales Turnover) & $22(25)$ \\
$<£ 1 m$ & $34(38)$ \\
$£ 1-10 \mathrm{~m}$ & $0(0)$ \\
$£ 11-100 \mathrm{~m}$ & $1(1)$ \\
$£ 100-500 \mathrm{~m}$ & $29(33)$ \\
$£ 501-1 \mathrm{bn}$ & $3(3)$ \\
$£>£ 1 b n$ & \\
Size (Number of Employees) & $44(49)$ \\
Small (N<50) 239 & $46(51)$ \\
Medium (50<N<250) & \\
\hline *missing values; valid percentages used.
\end{tabular}


Table 2 Most Popular SNS

\begin{tabular}{lll}
\hline & SNS & $\mathbf{N ~ ( \% ) *}$ \\
\hline 1 & Facebook & $17(77)$ \\
2 & LinkedIn & $11(46)$ \\
3 & Twitter & $12(55)$ \\
4 & Other & $2(9)$ \\
5 & MySpace & $1(5)$ \\
\hline
\end{tabular}

*missing values; valid percentages used. 
Table 3 Reasons for Using SNS

\begin{tabular}{lll}
\hline & Reasons & N (\%)* \\
\hline 1 & To attract new customers & $20(91)$ \\
2 & To cultivate relationships & $19(86)$ \\
3 & To increase awareness & $18(82)$ \\
4 & To communicate the brand online & $16(73)$ \\
5 & To receive feedback & $10(46)$ \\
6 & To interact with suppliers & $3(14)$ \\
\hline
\end{tabular}

*missing values; valid percentages used. 
Table 4 Measures of SNS Effectiveness in Supporting B2B brands

\begin{tabular}{lll}
\hline & Measures of Effectiveness & N (\%)* \\
\hline 1 & Numbers of users joining group & $8(73)$ \\
2 & Number of comments & $6(55)$ \\
2 & Number of positive comments & $6(55)$ \\
2 & Number of negative comments & $6(55)$ \\
2 & Number of customers attracted via SNS & $6(55)$ \\
3 & Number of friend requests & $5(46)$ \\
\hline
\end{tabular}

*missing values; valid percentages used. 
Table 5 Barriers of Using SNS

$\begin{array}{ll}\text { Barriers } & \text { N (\%)* }\end{array}$

$1 \quad$ SNS are not important within the industry the company 40 (61) operates

2 Uncertainty whether or how SNS could help brands 29 (44)

3 Staff is not familiar with SNS 21 (32)

4 SNS require a big investment in terms of time 15 (23)

4 Competitors do not use SNS 15 (23)

5 Staff do not have the technical skills to use SNS 10 (15)

*missing values; valid percentages used. 


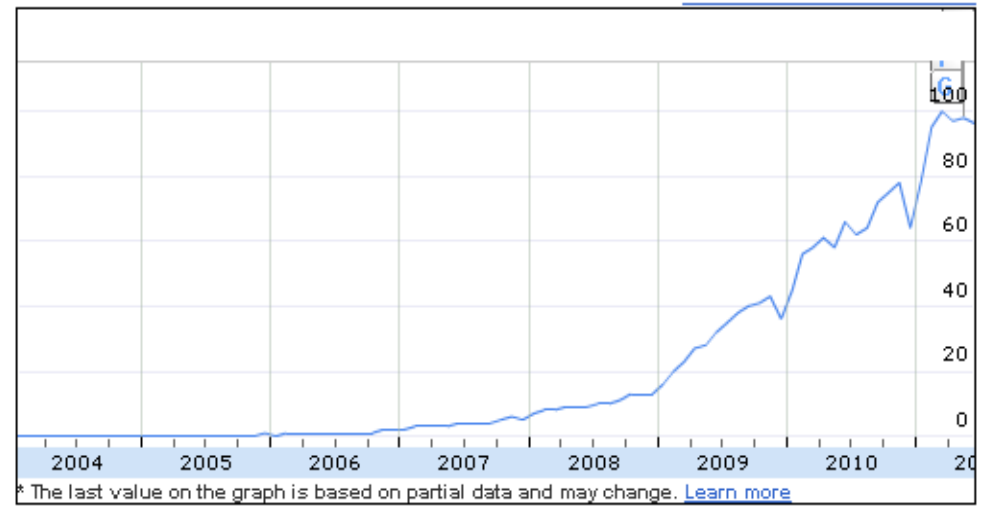

Figure 1: Google trends searching for "Social media" 


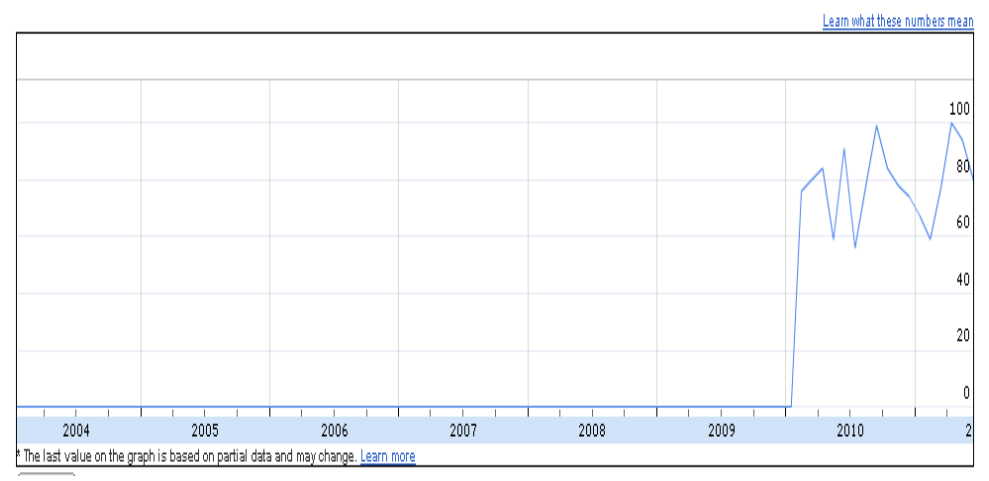

Figure 2: Google trends searching for "Social media" and B2B 